EXTENDED REPORT

\title{
Astigmatism in Chinese preschool children: prevalence, change, and effect on refractive development
}

\author{
D S P Fan, S K Rao, E Y Y Cheung, M Islam, S Chew, D S C Lam
}

Br J Ophthalmol 2004;88:938-941. doi: 10.1136/bjo.2003.030338

See end of article for authors' affiliations

Correspondence to:

Professor D S C Lam

Chairman and Professor Department of

Ophthalmology \& Visual

Sciences, The Chinese

University of Hong Kong,

3/F, University Eye Center,

Hong Kong Eye Hospital,

147K Argyle Street,

Kowloon, Hong Kong

dennislam@cuhk.edu.hk

Accepted

3 November 2003

\begin{abstract}
Aim: To study the prevalence, type, and progression of astigmatism in Chinese preschool children, and its effect on refractive development.

Methods: A cross sectional study of preschool children was carried out in two randomly selected kindergartens. A cohort study was performed on a subset of children, five years after initial examination. Refractive error (measured by cycloplegic autorefraction) and axial ocular dimensions (measured by ultrasonography) were the main study outcomes.

Results: 522 children participated in the study; the mean age was 55.7 months (SD 10.9; range 27 to 77 ). Mean cylinder reading was $-0.65 \mathrm{D}$ (SD 0.58 ; range 0.00 to -4.75 ), and with the rule astigmatism was predominant (53\%). In the 108 children studied longitudinally, the mean cylinder reading reduced from $-0.62 \mathrm{D}$ to $-0.50 \mathrm{D}(p=0.019)$. The presence of astigmatism in initial examination predisposed the eyes towards greater myopisation $(p<0.001)$. In addition, children with increased astigmatism had greater myopic progression $(p<0.001)$ and axial length growth $(p=0.002)$.

Conclusions: This study reports a high prevalence of astigmatism in Chinese preschool children. The presence of astigmatism, and particularly with increasing astigmatism, appears to predispose the children to progressive myopia. Further studies are warranted.
\end{abstract}

T he occurrence of astigmatism has been documented in $8 \%$ to $10 \%$ of adults. ${ }^{1}$ The reported prevalence of this refractive error in children was quite varied, and was influenced by age. ${ }^{2}$ In infants, studies have reported prevalence rates as high as $70 \%$ for astigmatism of more than 1 dioptre (D). ${ }^{3}$ Other studies have indicated that the prevalence of astigmatism decreased in older children to about $12-13 \%$ by the age of 10 years. ${ }^{4}$ A change in the axis of astigmatism with age was also described. In a study by Dobson et al, ${ }^{4}$ against the rule (ATR) astigmatism was 2.5 times more common than with the rule (WTR) in children younger than 3.5 years of age. In contrast, WTR astigmatism was three times more common in children older than 5.5 years.

Racial variations were also known to influence the prevalence and degree of astigmatism. ${ }^{5}$ A high prevalence of astigmatism has been described in American Indian children. ${ }^{6}$ This difference was attributed to the Mongoloid facial characteristics in this population, with higher lid tension. As American Indians are racially related to the Chinese and have a similar eyelid structure, it would be interesting to investigate whether a similar high prevalence of astigmatism is present in Chinese children.

A study in 570 Chinese children aged 36-65 months reported that $38.6 \%$ of the children had an astigmatic error of $-0.50 \mathrm{D}$ or more, and over $80 \%$ of the astigmatism was WTR. ${ }^{7}$ However, there was no longitudinal study on the changes in astigmatism among preschool children in Chinese population. In addition, astigmatism has been reported to be associated with the development of amblyopia, ${ }^{89}$ and progression of myopia. ${ }^{10}{ }^{11}$ These effects of astigmatism might be more significant if presented in a developing visual system. In this study, we estimated the prevalence of astigmatism in a cross sectional study of Chinese preschool children aged 2-6 years. We also examined a subset of the original cohort five years after the initial examination, to study the changes of astigmatism during development and its effect on myopic progression in children.

\section{MATERIALS AND METHODS}

Over $90 \%$ of children aged from 3 to 6 attend kindergarten in Hong Kong. ${ }^{12}$ We used a cluster sampling method and the sampling frame consisted of all 771 kindergartens in Hong Kong. Two kindergartens were randomly selected and all children attending these kindergartens were invited to participate. The purpose and procedures of the study were explained to the parents before obtaining informed consent. In addition, the ophthalmic examination was carried out on site in order to facilitate participation. Verbal consent was also obtained from each child before the examination. The protocol was approved by the Ethics Committee of The Chinese University of Hong Kong, and the study and measurements followed the guidelines of Declaration of Helsinki.

Examination included visual acuity testing by Sheridan Gardener test, and the best corrected visual acuity was performed if visual acuity was less than 20/30. Ocular movements and the pupillary reflex were examined, and cover-uncover testing to detect strabismus was performed. Cyclopentolate 1\% (Cyclopentolate Thilo, Dr Thilo \& Co, GmbH, Freiburg, Germany) and tropicamide 1\% (Mydriacyl, Alcon-Couvreur, Puurs, Belgium) were instilled three times in both eyes of the subjects at 10 minute intervals to produce cycloplegia. Cycloplegic refraction was performed using an autorefractometer (Topcon KR-7100 autokeratorefractometer, Topcon Corporation, Tokyo, Japan). The refractive error was recorded in the minus cylinder format. Ultrasound biomicroscopy (Storz Compuscan, Storz Ophthalmic Inc, St Louis, MO, USA) was performed after instilling paracaine $1 \%$ eye drops. In order to improve the cooperation of the children, the principal and school teachers accompanied the children during examination. Moreover, older and more cooperative children were examined first. Three consistent readings were obtained, and the average of these values was

Abbreviations: ATR, against the rule; SER, spherical equivalent refraction; WTR, with the rule. 
used for analysis. The presence of a red fundal reflex was verified after pupillary dilatation.

Astigmatism was analysed in minus cylinders, and was defined as less than $-1.00 \mathrm{D}$ of cylinder. The axis of any cylindrical component was classified as WTR if the minus cylinder axis was within $15^{\circ}$ of $180^{\circ}$, ATR for minus cylinder axis within $15^{\circ}$ of $90^{\circ}$, or oblique (other than WTR or ATR). ${ }^{2}$ Spherical equivalent refraction (SER) was calculated as summation of spherical component and half of cylindrical component. These definitions were chosen to enable comparison with other studies. ${ }^{4}{ }^{10} 13-16$

A total of 237 children from one kindergarten who participated in the cross sectional study was invited for cohort study. A subset of 108 children from the original cohort was re-examined five years later. Reasons for the smaller number in the follow up study included the following: children had moved to another area, had found another eye care provider, or were not willing to have the follow up examinations. The initial SER, astigmatism, and axial length were not significantly different for children in this subset compared with those not participating in the cohort (Student's $t$ test, $\mathrm{p}=0.361 ; 0.897 ; 0.697$, respectively).

Statistical analysis was performed using SPSS 10.0 for Windows (SPSS Inc, Chicago, IL, USA). The correlations of refraction and ultrasound biometric parameters were performed using the Pearson correlation. Student's $t$ test was used to compare variables between the initial and final examinations. ANOVA test was employed for comparison among different axis groups. A p value of less than 0.05 was considered significant.

\section{RESULTS}

A total of 697 children from the two randomly selected kindergartens were invited to take part in this study and 605 children agreed to participate. The response rate was $86.8 \%$. After those who had ocular or major medical diseases were excluded, $594(85.2 \%)$ enrolled. Four children with strabismus, three children with amblyopia, two children with history of prematurity, one child with hearing disease, and one child with cardiac valvular disorder were excluded. The ocular examination was completed in 522 children $(74.9 \%)$. This included 241 girls and 281 boys, aged 27-77 months (mean 55.7 months; standard deviation (SD) 10.9 months). The correlation of SER between the right and left eyes was high $(\mathrm{p}=0.845)$. Refractive data of the right eyes of subjects were analysed. ${ }^{17}$

\section{Prevalence of astigmatism}

The mean refractive error in the right eye of these children was $0.89 \mathrm{D}$ ( SD $0.84 \mathrm{D}$; range -4.00 to $5.00 \mathrm{D}$ ). The mean cylinder reading in these 522 eyes was $-0.65 \mathrm{D}$ (SD $0.58 \mathrm{D}$; range 0.00 to $-4.75 \mathrm{D}$ ). The distribution of astigmatic errors is shown in figure 1. An astigmatic error of $0.50 \mathrm{D}$ or greater was seen in $55.8 \%$ of the children, $1.00 \mathrm{D}$ or greater was seen in $21.1 \%$, and $2.2 \%$ had an error greater than $2.00 \mathrm{D}$. There was no significant difference in the occurrence of astigmatism between boys and girls (Student's $t$ test, $\mathrm{p}=0.425$ )

The distribution of WTR, ATR, and oblique astigmatism in the 445 eyes was $53.0 \%, 7.9 \%$, and $39.1 \%$ respectively. The distribution of astigmatic error and axis in the different age groups is described in table 1 . There was no relation between age group and the prevalence of astigmatism $\left(\chi^{2}, p=0.858\right)$. A gradual increase in WTR astigmatism in older children and a decrease in the prevalence of ATR astigmatism were noted. This trend though was not statistically significant $\left(\chi^{2}\right.$, $\mathrm{p}=0.470$ ). The prevalence of oblique astigmatism was relatively constant in the different age groups.

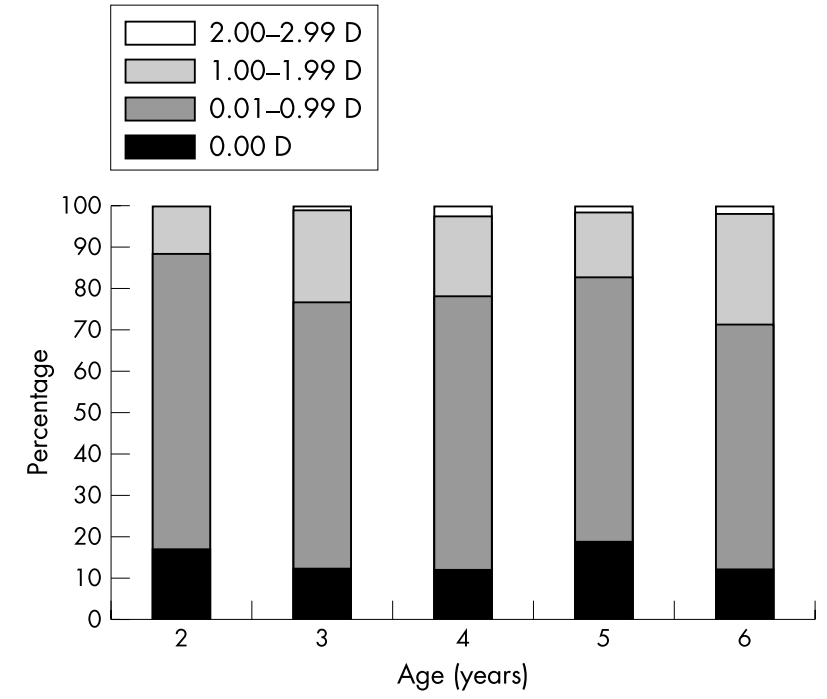

Figure 1 Distribution of astigmatism in 522 eyes of Chinese preschool children.

\section{Changes in astigmatism}

A total of 233 children attending one of the two kindergartens were invited to participate into the cohort study. A subset of 108 children (45.6\%) was re-examined five years later. The mean age of children was 9.3 years (SD 0.89; range 8 to 11 years). Sixty three children $(58.3 \%)$ had astigmatism of at least 0.50 D. Fourteen children (12.9\%) had astigmatism $(\geqslant 1.00 \mathrm{D})$. Two children ( $1.9 \%)$ had astigmatism more than $2.00 \mathrm{D}$. Out of the 84 children who did not have astigmatism $(\geqslant 1.00 \mathrm{D})$ in initial examination, nine children $(10.7 \%)$ acquired astigmatism $(\geqslant 1.00 \mathrm{D})$ in the final examination. On the other hand, of the 24 children who had at least $1.00 \mathrm{D}$ astigmatism in the initial examination, 19 of them $(79.2 \%)$ had a decrease in astigmatism to less than $1.00 \mathrm{D}$ at the final examination.

The mean cylinder reading was $-0.50 \mathrm{D}$ (SD 0.49; range 0.00 to -3.25$)$ at the end of the study, which was significantly lower than that in the initial examination, which was $-0.62 \mathrm{D}$ (SD 0.43 ; range 0.00 to -2.50 ) (Student's $t$ test, $\mathrm{p}=0.019$ ). Moreover, 55 children $(50.9 \%)$ had decreased cylindrical value whereas 19 children (17.6\%) had no change. Thirty four children $(31.5 \%)$ had increased in astigmatism.

In the initial examination, 97 out of the 108 children had astigmatism. With the rule astigmatism occupied the major portion $(51.6 \%$ ) whereas $9.3 \%$ were ATR and $39.2 \%$ were oblique astigmatism. In the final examination, 84 children had astigmatism. The percentage of WTR astigmatism dropped to $36.9 \%$. The percentages of ATR astigmatism and oblique astigmatism were $15.5 \%$ and $47.6 \%$ respectively. However, this was not statistically significant $\left(\chi^{2}, \mathrm{p}=0.776\right)$.

\section{Relation between astigmatism and myopia}

The relation between astigmatism and myopic development was studied in the subset of 108 children. At the initial examination, the higher the astigmatism, the more hyperopic the children were in terms of spherical readings $(r=-0.226$, $\mathrm{p}=0.018)$. However there was no association between astigmatism and SER $(r=0.036 ; \mathrm{p}=0.710)$ and axial length $(r=0.088 ; 0.375)$. After five years, a higher degree of astigmatism at initial examination was associated with more myopic spherical refraction $(r=0.231, \mathrm{p}=0.036)$ and more myopic SER $(r=0.364, \mathrm{p}<0.001)$. In addition, these children had longer axial length $(r=-0.280, \mathrm{p}=0.004)$. Changes in refractive error and axial length, obtained by subtracting 
Table 1 Astigmatic error and axis at different ages in the study group

\begin{tabular}{|c|c|c|c|c|c|}
\hline \multirow[b]{2}{*}{$\begin{array}{l}\text { Age (number } \\
\text { of eyes) }\end{array}$} & \multirow[b]{2}{*}{$\begin{array}{l}\text { Astigmatism (D) } \\
\text { mean (SD) (range) }\end{array}$} & \multicolumn{4}{|c|}{ Number of eyes (\%) } \\
\hline & & Nil & With the rule & $\begin{array}{l}\text { Against } \\
\text { the rule }\end{array}$ & Oblique \\
\hline$\leqslant 2.9$ years $(17)$ & $\begin{array}{l}-0.53(0.46) \\
(0.00-1.75)\end{array}$ & $3(17.6 \%)$ & $6(35.3 \%)$ & $3(17.6 \%)$ & $5(29.4 \%)$ \\
\hline 3 to $3.9(126)$ & $\begin{array}{l}-0.64(0.48) \\
(0.00-2.50)\end{array}$ & $15(11.9 \%)$ & $56(44.4 \%)$ & $12(9.5 \%)$ & $43(34.1 \%)$ \\
\hline 4 to $4.9(165)$ & $\begin{array}{l}-0.68(0.55) \\
(0.00-3.00)\end{array}$ & $20(12.1 \%)$ & 79 (47.9\%) & $10(6.1 \%)$ & $56(33.9 \%)$ \\
\hline 5 to $5.9(172)$ & $\begin{array}{l}-0.64(0.69) \\
(0.00-4.75)\end{array}$ & $33(19.2 \%)$ & $75(43.6 \%)$ & $7(4.1 \%)$ & $57(33.1 \%)$ \\
\hline$\geqslant 6.0(42)$ & $\begin{array}{l}-0.70(0.51) \\
(0.00-2.00)\end{array}$ & $6(14.3 \%)$ & $20(47.6 \%)$ & $3(7.1 \%)$ & $13(31.0 \%)$ \\
\hline
\end{tabular}

initial examination results from the final examination results, were also studied. Children with higher astigmatism in initial examination had more myopic shift $(r=0.312$, $\mathrm{p}=0.001)$ and longer axial length growth $(r=-0.284$, $\mathrm{p}=0.04$ ) at the final examination. However, the axis of astigmatism was not related to the myopic shift (ANOVA, $p=0.581)$ and axial length growth (ANOVA, $p=0.614$ )

Thirty four children $(31.5 \%)$ had increased in astigmatism over the five year period. Compared with children with stable or reduction in astigmatism, these children had more myopic spherical refraction $(t$ test, $\mathrm{p}<0.001)$, SER $(t$ test, $\mathrm{p}<0.001)$ and myopic shift ( $t$ test, $\mathrm{p}<0.001)$. Moreover, they also had longer axial length ( $t$ test, $\mathrm{p}=0.001$ ) and longer axial length growth ( $t$ test, $\mathrm{p}=0.002)$, as shown in table 2 . In addition, mean myopic progression (ANCOVA, $p<0.001$ ) and axial length growth (ANCOVA, $\mathrm{p}=0.003$ ) was higher among children with increased astigmatism (myopic progression $=-2.43 \mathrm{D}$; axial length change $=2.22 \mathrm{~mm}$ ) than children with stable or reduction in astigmatism (myopic progression $=-0.98 \mathrm{D}$; axial length change $=1.22 \mathrm{~mm}$ ) when age was controlled.

\section{DISCUSSION}

Although the high occurrence of astigmatism in the eyes of infants is well established, the reason for this is not clear. As the astigmatism decreases rapidly as the child grows, and reaches adult levels by 18 months of age, ${ }^{1}$ it has been postulated that astigmatism in infancy is useful in establishing normal accommodative feedback loops. ${ }^{18}$ Experiments in chicks have also established that artificially imposed astigmatism, using spectacle lenses, can result in altered ocular growth patterns. ${ }^{17}$ Therefore, it is generally believed that cylindrical errors, unless huge, may not affect the retinal

Table 2 Comparison of ocular parameters in children with increased astigmatism with children with decreased or no change in astigmatism in the cohort

\begin{tabular}{lccr}
\hline & $\begin{array}{l}\text { No change or } \\
\text { decrease in } \\
\text { astigmatism } \\
\text { (74 cases) }\end{array}$ & $\begin{array}{l}\text { Increase in } \\
\text { astigmatism } \\
\text { (34 cases) }\end{array}$ & p Value \\
\hline Ocular parameter & $0.27(1.40)$ & $-1.19(1.72)$ & $<0.001$ \\
Spherical error (D) & $0.11(1.40)$ & $-1.62(1.78)$ & $<0.001$ \\
SER (D) & $-0.93(1.08)$ & $-2.01(1.42)$ & $<0.001$ \\
Spherical error & & $-2.25(1.43)$ & $<0.001$ \\
change (D) & $-0.72(1.08)$ & $24.10(0.87)$ & 0.001 \\
SER change (D) & $23.48(0.89)$ & $2.07(0.70)$ & 0.002 \\
Axial length (mm) & $1.55(0.80)$ & & \\
Axial length change & & & \\
(mm) & & & \\
\hline D, dioptres; SER, spherical equivalent refraction. \\
Results are shown as mean (standard deviation).
\end{tabular}

image of very young eyes. ${ }^{9}$ However, it has been suggested that, as a child grows older, myopia can progress in uncorrected astigmatism. ${ }^{910}$ Therefore, the role of astigmatism on visual development has not yet been completely understood.

The prevalence of astigmatism has varied in different studies in different populations. ${ }^{341617}$ The data from our study indicate a high prevalence of astigmatism in Chinese preschool children compared with previously published reports. We found that astigmatism $(\geqslant 1.00 \mathrm{D})$ was found in $21.1 \%$ of preschool children (mean age 55.7 months). Howland et al reported that one out of 10 children of age 4 years or more had $1.00 \mathrm{D}$ or greater astigmatism. ${ }^{3}$ Dobson et al reported that astigmatism of $1.00 \mathrm{D}$ or more was found in $25 \%$ of the children aged $1-48$ months. ${ }^{4}$ Mayer also showed that $25 \%$ of children with same age group had astigmatism $(\geqslant 1.00 \mathrm{D}) .{ }^{14}$ The prevalence of astigmatism among Chinese (aged 6 to 7 years) in Singapore was $17.1 \% .^{16}$ Compared with a previous study in Hong Kong by Chan and Edwards ${ }^{17}$ in children with a mean age of 51.8 months, our results show a higher prevalence of astigmatism. In our study, astigmatism of $0.50 \mathrm{D}$ or more was observed in $55.8 \%$ of the children. In contrast, Chan and Edwards reported astigmatism of $0.50 \mathrm{D}$ or more in $38.6 \%$. We estimated cycloplegic refraction in our study, unlike the study of Chan and Edwards, ${ }^{17}$ in which non-cycloplegic refractions were obtained. This might account for some of the differences. ${ }^{3}{ }^{19}$

The amount of astigmatism seen in different age groups is described in table 1 . In contrast to previous studies which showed that the prevalence of astigmatism decreased with age, ${ }^{2}$ the trend of increasing astigmatism in older children was observed, although this was not statistically significant $(p=0.470)$. Similar to that reported in an earlier study, ${ }^{2-4} 9$ the predominant type of astigmatism in our study was WTR $(53.2 \%)$, although this was less than the $80 \%$ prevalence reported earlier. ${ }^{7}$ Gwiazda et al reported that among the 19 children who did not show astigmatism in the first year, only one acquired it by 4 years. ${ }^{2}$ They concluded that if a child did not have astigmatism in infancy, he or she was unlikely to acquire it at a later age, at least up to 4 to 6 years of age. Although we found that there was a decrease in the mean cylindrical value, $17.6 \%$ had no change and $31.5 \%$ had an increase in astigmatism. Moreover, $10.7 \%$ of the children acquired astigmatism ( $\geqslant 1.00 \mathrm{D})$ during the five year period. In summary, compared with previous studies, we had a higher prevalence of stable astigmatism among preschool children in Hong Kong. A significant proportion of children acquired astigmatism during development.

The association between astigmatism and myopia is controversial. The results from Parssinen ${ }^{20}$ did not support the causal relation between astigmatism and myopic progression. However, this study was confined to older children 
( $>10$ years), whose development was more or less completed. On the other hand, Fulton et al described the relations between increasing myopic SER and an increase in astigmatism in their study of 298 children (aged from $0-10$ years). ${ }^{9}$ In children of all age groups, they found that the myopic SER were greater in eyes with astigmatism more than $1.00 \mathrm{D}$. The mean SER in astigmats $(1.00 \mathrm{D}$ or more difference in refractive power of orthogonal meridia) was -4.9 (SD 5.6) D compared with non-astigmats, -1.8 (SD 2.4) D $(p<0.01)$. They indicated that astigmatism in children, particularly of higher degrees $(\geqslant 3 \mathrm{D})$, might lead to visual blurring perturbations that could trigger development of myopia, similar to that seen in animal models. ${ }^{11}{ }^{18}$ In our study, astigmatism greater than $2 \mathrm{D}$ was observed in only 11 $(2.2 \%)$ of the children, unlike their study population in which 45 eyes had $\geqslant 3 \mathrm{D}$ of astigmatism. In addition, Fulton et al selected patients with $\geqslant 0.25 \mathrm{D}$ astigmatism in one or both eyes to constitute the study population, they also included cases with eye diseases including amblyopia, prematurity, and strabismus. ${ }^{9}$ Only healthy preschool children with no previous eye diseases other than refractive error were recruited in our study. Moreover, to the best of our knowledge, our study was the first one to investigate the relation between astigmatism and ocular dimensions in preschool children in a longitudinal study. Special precautions, including children being accompanied by the teachers during examination, and older and more cooperative children being examined first improved the success rate. Of the 594 children, $522(87.9 \%)$ were able to complete the cycloplegic refraction and ultrasound biomicroscopy.

Our results not only showed that higher astigmatism was associated with more myopic refraction and more myopic shift, but also suggested that astigmatism was related to longer axial length and axial length growth. Thus, our data further substantiate the hypothesis that stable astigmatism in preschool children is associated with greater progression of myopia in subsequent years. ${ }^{9}{ }^{10}$ Previous studies showed that astigmatism decreased with age. ${ }^{127131421-24}$ Although we found that the mean astigmatism decreased from -0.62 (SD 0.43 ) $\mathrm{D}$ in the initial examination to -0.50 (SD 0.49 ) $\mathrm{D}$ in the final examination $(\mathrm{p}=0.019), 34$ children $(31.5 \%)$ had increased in astigmatism. In addition, compared to those with decrease or no change in astigmatism, these children had more myopic progression $(-0.72$ (SD 1.08) D $v-2.25$ (SD 1.43) D) and axial length increase ( 1.55 (SD 0.80) $\mathrm{mm} v$ 2.07 (SD 0.70) mm).

Astigmatism blurs pattern vision, and thus raises the possibility that astigmatism might influence the development of myopia. ${ }^{10}$ There was also a proposal that the structural link between axial myopia progression and accommodation could be extended to include astigmatism. ${ }^{10}$ On the other hand, previous studies have shown that ATR astigmatism was more prone to myopic development, ${ }^{10}$ even though we could not show similar results because of the limited sample size. The refraction and myopic progression were not related to the axis groups.

We recognised that the longitudinal follow up study group had a smaller number of children. Despite our best efforts, we could not increase the number followed up in this group. However, the 108 children in the follow up study were similar to those from the original cohort who were not examined again, in terms of SER, astigmatism, and axial length.

In conclusion, we reported a higher incidence of astigmatism in Chinese preschool children than those previously reported. The predominant astigmatism in these young children was WTR. Follow up evaluation in a subset of these children showed that a significant percentage of children had stable and even increased astigmatism. In addition, our results supported the hypothesis that an increase in astigmatism in children can lead to an increased occurrence and progression of myopia. Further studies on how astigmatism leads to myopic development and whether early correction of astigmatism can prevent myopia progression are warranted.

\section{Authors' affiliations}

D S P Fan, E Y Y Cheung, M Islam, D S C Lam, Department of Ophthalmology and Visual Sciences, The Chinese University of Hong Kong, Hong Kong Eye Hospital, Kowloon, Hong Kong, People's Republic of China

S K Rao, Sankara Nethralaya, Medical and Vision Research Foundations, Chennai, India

S Chew, Singapore Eye Research Institute, Singapore

Financial interest: none.

\section{REFERENCES}

1 Atkinson J, Braddick O, French J. Infant astigmatism: its disappearance with age. Vision Res 1980;20:891-3.

2 Gwiazda J, Scheiman M, Mohindra I, et al. Astigmatism in children: changes in axis and amount from birth to six years. Invest Ophthalmol Vis Sci 1984;25:88-92.

3 Howland HC, Sayles N. Photorefractive measurements of astigmatism in infants and young children. Invest Ophthalmol Vis Sci 1984;25:93-102.

4 Dobson V, Fulton AB, Sebris SL. Cycloplegic refractions of infants and young children: the axis of astigmatism. Invest Ophthalmol Vis Sci 1984;25:83-7.

5 Lam CS, Goh WS. Astigmatism among Chinese school children. Clin Exp Optom 1991;74:150.

6 Lyle WM, Grosvenor T, Dean KC. Corneal astigmatism in Amerind children. Am J Optom Arch Am Acad Optom 1972:49:517-24.

7 Abrahamsson M, Fabian G, Sjostrand J. A longitudinal study of a population based sample of astigmatic children. II. The changeability of anisometropia. Acta Ophthalmol (Copenh) 1990;68:435-40.

8 Alward WL, Bender TR, Demske JA, et al. High prevalence of myopia among young adult Yupik Eskimos. Can J Ophthalmol 1985;20:241-5.

9 Fulton $A B$, Hansen RM, Petersen RA. The relation of myopia and astigmatism in developing eyes. Ophthalmology 1982;89:298-302.

10 Gwiazda J, Grice K, Held R, et al. Astigmatism and the development of myopia in children. Vision Res 2000;40:1019-26.

11 Howland HC. Infant eyes: optics and accommodation. Curr Eye Res 1982;2:217-24.

12 Census and Statistics Department. Hong Kong Population Census: The department, 2001. HKSAR

13 Abrahamsson M, Fabian G, Sjostrand J. Changes in astigmatism between the ages of 1 and 4 years: a longitudinal study. Br J Ophthalmol 1988;72:145-9.

14 Mayer DL, Hansen RM, Moore BD, et al. Cycloplegic refractions in healthy children aged 1 through 48 months. Arch Ophthalmol 2001;119:1625-8.

15 Miller JM, Dobson V, Harvey EM, et al. Comparison of preschool vision screening methods in a population with a high prevalence of astigmatism. Invest Ophthalmol Vis Sci 2001;42:917-24.

16 Zhan MZ, Saw SM, Hong RZ, et al. Refractive errors in Singapore and Xiamen, China-a comparative study in school children aged 6 to 7 years. Optom Vis Sci 2000;77:302-8.

17 Chan OY, Edwards M. Refractive errors in Hong Kong Chinese pre-school children. Optom Vis Sci 1993;70:501-5.

18 Schmid K, Wildsoet CF. Natural and imposed astigmatism and their relation to emmetropization in the chick. Exp Eye Res 1997;64:837-47.

19 Harvey EM, Miller JM, Dobson V, et al. Measurement of refractive error in Native American preschoolers: validity and reproducibility of autorefraction. Optom Vis Sci 2000;73:140-9.

20 Parssinen O. Astigmatism and school myopia. Acta Ophthalmol (Copenh) 1991:69:786-90.

21 Howland HC, Sayles N. Photorefractive measurements of astigmatism in infants and young children. Invest Ophthalmol Vis Sci 1984;25:93-102.

22 Dobson V, Fulton AB, Sebris SL. Cycloplegic refractions of infants and young children: the axis of astigmatism. Invest Ophthalmol Vis Sci 1984;25:83-7.

23 Abrahamsson M, Fabian G, Sjostrand J. A longitudinal study of a population based sample of astigmatic children. II. The changeability of anisometropia. Acta Ophthalmol (Copenh) 1990;68:435-40.

24 Mayer DL, Hansen RM, Moore BD, et al. Cycloplegic refractions in healthy children aged 1 through 48 months. Arch Ophthalmol 2001;119:1625-8. 